\title{
Challenges Pupils Face in Learning Phonological Skills: A Case of Bunda District, Tanzania
}

\author{
Amani Mramboa \\ Orcid: https://orcid.org/0000-0003-0065-9916 \\ Department of Languages and Linguistics, St. Augustine University of Tanzania \\ Email: amanimramboa@gmail.com \\ Nestory Ligembe, PhD \\ Orcid: https://orcid.org/0000-0003-2896-4306 \\ Department of Languages and Linguistics, St. Augustine University of Tanzania \\ Email: nligemb@yahoo.co.uk \\ Corresponding Mail: nligemb@yahoo.co.uk
}

\begin{abstract}
Copyright resides with the author(s) in terms of the Creative Commons Attribution CC BY-NC 4.0. The users may copy, distribute, transmit and adapt the work, but must recognize the author(s) and the East African Journal of Education and Social Sciences
\end{abstract}

\begin{abstract}
This study assessed pupils' phonological awareness (PA) skills in reading English language among Primary Schools in Bunda, Tanzania. The study was guided by the Interactive Theory developed by Rumelhart (1980) that views reading as a process which employs both the top -down and the bottom -up processes. Collection of data was done by using interviews, focus group discussions and tests. Data collection was also done through classroom observations, interviews, focus group discussions and tests. The major findings revealed that majority pupils in public primary schools and some in English medium schools had low phonological awareness skills. The pupils faced difficulties in pronouncing words with consonant clusters and in decoding digraphs; they also faced difficulties in recognizing silent sounds and in o decoding words with irregular Grapheme Phoneme Correspondences (GPC). Pupils inserted phonemes within consonant blends and in word finals as a result of Kiswahili and mother tongue influences. The study concluded that pupils will excel in learning phonological skills if teachers strictly employ phonics strategies such as segmentation, blending, substitution, deletion and rhyming games. Moreover, teachers in English medium primary schools and their colleagues in public schools should work closely together in addressing the strategies and techniques of imparting phonological awareness skills to pupils.
\end{abstract}

Keywords: Phonological awareness; phonemic awareness; synthetic phonics; analytical phonics; decoding

How to cite: Mramboa, A. and Ligembe, N. (2022). Challenges Pupils Face in Learning Phonological Skills: A Case of Bunda District, Tanzania. East African Journal of Education and Social Sciences 3(1), 49-60. Doi: https://doi.org/10.46606/eajess2022v03i01.0145.

\section{Introduction}

This study focused on assessing pupils' phonological awareness skills in reading English language. The study was motivated by the assumption that pupils to lack phonological awareness skills is a big problem because they may face a lot of challenges including failure to pronounce words correctly and spell words accurately in dictation lessons. Pupils with poor phonological awareness skills face difficulties in word recognition, reading fluency and comprehension (National Reading, 2000).

Furthermore, pupils who lack phonological awareness skills usually find it difficult to blend and segment phonemes in words and they are unable to recognize syllable onset-rhyme structures, hence read with difficulties (Woldmo, 2018).These 
arguments suggest that phonological awareness skills are of vital significance in reading skills development. The skills enable learners to integrate written materials and learn language independently through familiarity with dictionaries, other books, newspapers and materials in the internet.

In Tanzania pupils' reading situation is worse because majority of them complete primary schools with very low phonological awareness skills and English language reading ability, while almost all of the secondary school reading materials and examinations are written in English language. A study conducted by Uwezo (2019) reveals that in the year 2017 more than fifty per cent of standard seven leavers in Tanzania failed to read a standard two-level English stories. This denotes that the pupils were not able to transform the graphic symbols into phonological symbols. However, notwithstanding the fact that phonological awareness is influential in developing learners' recognition of words, reading fluency and comprehension, little attention has been paid on assessing pupils' progress in acquisition of phonological skills and the efficiency of the strategies of enhancing such skills to pupils in Tanzanian primary schools. Some studies (Msabaha 2018, Mtallo and Mwambula, 2018) made attempts to assess how languages influence each other phonologically. For example, Msabaha assessed the influence of Kiswahili phonological structures towards the acquisition of English language pronunciation skills in Songea District. Findings revealed that majority of pupils pronounced English language words the way they pronounced Kiswahili words.

Woldmo (2018) proclaims that phonological awareness is an umbrella term which covers basic awareness of speech sounds, understanding that phonemes can build onset-rimes and onset-rimes make up syllables. It also denotes the knowledge that syllables can be blended to form words and the ability to substitute sounds and letters to form words, and omitting letters and sounds to form new words. The awareness of phonemes enables learners to analyze and synthesize words for better pronunciation and spelling.

According to National Reading Panel (2000), phonemic awareness is an advanced stage of phonological awareness which symbolizes one's capability to attend to alphabetical analysis. Phonemic awareness denotes the capacity to focus on and operate speech sounds in the verbally presented words. An in-depth teaching, in the alphabetic principle essentially comprises a focus to phonemes since phonemes are the phonological elements that are related to the graphic symbols (letters of the alphabet).

Tanzanian pupils' reading skills development in English language seems to be more inadequate as a greater number of pupils fail to accomplish it compared to reading in Kiswahili. While $1 / 5$ of primary school leavers in 2017 could not read a standard two-level Kiswahili book, more than half of them could not read a standard two-level English stories (Uwezo, 2019). This implies that English language reading needs a closer attention. This also suggests that there is a need to assess the efficacy of the teaching strategies used by teachers in imparting English language reading skills.

This study assumed that despite the fact that Kiswahili and English use the International Phonetic Alphabet symbols in writing, English language reading becomes harder as there are some variations in the manner the letters are represented by sounds. While Kiswahili is a regular language in which letters are pronounced the way they are spelt in most of the words, many English words have no one-on-one correspondence between spelling and pronunciation (Msabaha, 2018).The discrepancies between orthography and phonology in English language are more challenging to readers (figure 1 ).

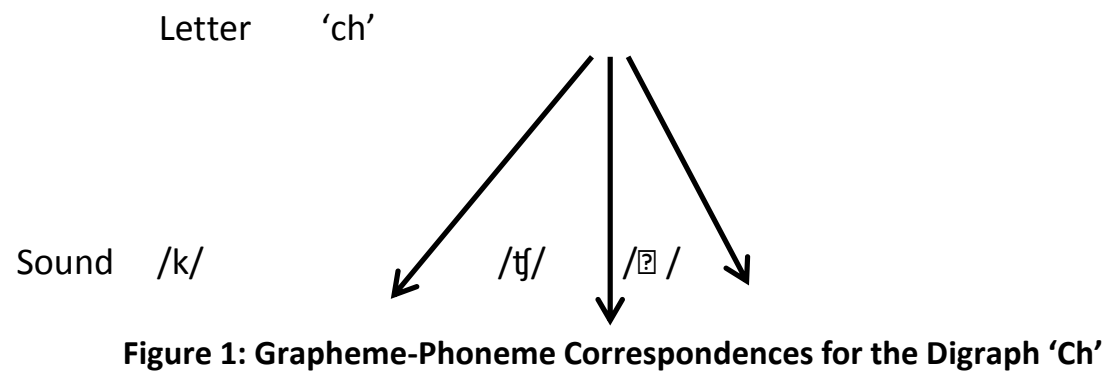

These views are supported by Rao (2018) who asserts that English language spelling and

pronunciation are really confusing, since there is a great deal of mismatch between them. For example, 
the consonant digraph 'ph' stands for different phonemes in spoken words. The digraph can be realized as a voiceless velar stop $/ \mathrm{k} /$ in the words 'chemist /kemist/, 'chorus' /kJ:rəs/ and 'cholera' /kplərə/. Also, the digraph 'ch' appears as a voiceless palatal alveolar affricate $/ t /$ in the words 'chair' / tea/, 'cheap' /ti:p/ and 'chop' / top/. On the other hand, the digraph 'ch' appears as a voiceless palatal alveolar fricative /? / in the words 'champagne', 'machete' and 'machine.'

Rao further substantiates that British English has 12 pure vowels and eight diphthongs but the letters are only five (a, e, i, o, u). Also, English consonants bring confusion as there are 24 consonants in the language represented by only 21 letters $(b, c, d, f, g$, $h, j, k, l, m, n, p, q, r, s, t, v, w, x, y, z)$.

Regarding Bunda Town, the situation on pupils' reading skills is not promising as various studies (Ligembe, 2014, Uwezo, 2019) reveal. For example, Ligembe (2014) conducted a study aiming at exploring the factors affecting pupils' acquisition of reading skills in Kiswahili in Mara and Mwanza regions in Tanzania. Findings revealed that in 2012, a total of 72 form one students including 31 girls and 41 boys in Bunda failed the literacy examinations.

Similarly, various scholars expose the challenges faced by pupils in developing reading skills. Among those scholars, Solak and Atlay (2014) conducted a research to determine types of reading strategies in Turkey where the findings revealed that reading difficulties among the ESL and EFL learners stem from various factors which include insufficient terminology, complicated language structures and linguistic unreachability.

Additionally, it is argued that the most reading difficulties that children face stem from unacquainted terminology as well as homonymy and homophony as cases where the same word has more than one meaning and where different word forms have a similar pronunciation(Kasim and Raisha, 2017).For example, the words pronounced /rait / appear in different forms such as 'rite,' 'right', 'write' and 'wright', hence causing great confusions to readers as they attempt to figure out the meaning of the words.

What is implied is that some of the challenges that pupils face in reading are linguistically-based as they are within the language. However, despite the attempts to identify the challenges that pupils face in reading, studies have not clearly suggested the mitigation measures to solving the problem. Thus, this study intended to cover that gap by exploring various challenges that pupils face in developing phonological awareness skills for better reading in English language.

Other studies (McArthur \& Castles, 2017; Rao, 2018; Sipra, 2013) assert that English orthography acts as one of the major impediments obstructing the acquisition of reading skills to learners. This is chiefly associated with the mismatch between letters and sounds in English language. It is from such discrepancies that Rao suggests that the International Phonetic Alphabet (IPA) charts can be used to acquire the sounds that represent letters of the alphabet in speech. Figure 2 shows the alphabetic chart for consonants.

\section{THE INTERNATIONAL PHONETIC ALPHABET (revised to 2018)}

CONSONANTS (PULMONC)

\begin{tabular}{|c|c|c|c|c|c|c|c|c|c|c|c|}
\hline & Biatial & ILtiodatialal & Destid & Alveolar $\mathrm{P}_{0}$ & salededat. & Retrofer & Patasal & \begin{tabular}{|l|} 
Velat \\
\end{tabular} & Uvilat & Pharyngeal & Glototal \\
\hline Plosive & $\mathrm{pb}$ & & & $\mathrm{td}$ & & $t d$. & $C \mathrm{f}$ & $\mathrm{kg}$ & $q G$ & & $?$ \\
\hline Nasal & $\mathrm{m}$ & $\mathrm{m}$ & & n & & $\eta$ & n & $\eta$ & $\mathrm{N}$ & & \\
\hline Till & B & & & $\mathrm{r}$ & & & & & $\mathrm{R}$ & & \\
\hline Tap orf Flapp & & r & & ᄃ & & r & & & & & \\
\hline Finctive & $\phi \beta$ & $f v$ & $\theta \partial$ & SZ & 3 & $\$ \&$ & $c j$ & X X & $\chi$ в & $\hbar \varrho$ & $\mathrm{hh}$ \\
\hline $\begin{array}{l}\text { Lataral } \\
\text { fifcraive }\end{array}$ & & & & $\mathrm{dz}$ & & & & & & & \\
\hline Aproximarts & & v & & I & & $\pi$ & $\mathrm{j}$ & प्य & & & \\
\hline ILtaral & & & & l & & & $\AA$ & $\mathrm{L}$ & & & \\
\hline
\end{tabular}

Figure 2: Alphabetic Chart for Consonants

51 East African Journal of Education and Social Sciences (EAJESS) 3(1)49-60 
It represents the consonants of English language alphabet. British English picks its 24 consonants from the inventory of the consonants from this International Alphabetic Chart for consonants.

\section{Theoretical Framework}

The study was guided by the Interactive Theory. According to Ngambut (2015) the Interactive Theory pronounced by Rumelhart (1980) views reading as a process that employs both the top -down and the bottom -up processes. It assumes that comprehension as the goal of reading is dependent on both graphic information and information in the reader's mind. In the interactive theory, reading is regarded as the thoughtful and meaningful interpretation of printed or written symbols while comprehension is the result of the interaction between the perceptions of graphic symbols representing language as well as the readers' language skills and world knowledge (Ngambut, 2015).

Similarly, McRae (2012) is of the view that the Interactive Theory is the theory of reading that takes into account the constant interface between the graphic symbols and readers' experience in the building of the denotation of a text. These views are seconded by Gonzalez (2017) who asserts that the Interactive Theory assumes that all the bottom-up and top-down processes cooperate in the general course of evolving reading skills to the pupils.

Commenting on the roles of the bottom-up processes, McRae asserts that the processes facilitate the building of the texts from the minimum units (letters to words to phrases to sentences), previously known as decoding. The bottom-up processes of teaching reading involve taking the small units of a text like letters, words, phrases and sentences and letting them be taught to children from simple to complex (Angonsto, Sánchez, Álvarez, Cuevas \& León (2013) ;Gilakjani \& Sabouri, 2016).

Bottom-up processing proposes that during the reading activity it is suitable to begin with phonological tactics that enable readers to be aware of the phonemes enclosed in the lexical items. Phonological tactics permit the readers to use grapheme-phoneme familiarity for effective reading and for construction of lexical items. Orthographic strategies are also of importance for letter identification, word knowledge and all what is associated with the writing structure (Mendez and Lliviganay (2017). The arguments by Mendez and
Lliviganay suggest that the bottom-up processes consider reading as the skill that requires application of strategies that develop reading skills systematically. The learning focus on breaking down the reading process into smaller components like letters of the alphabet and their corresponding sounds and then proceed towards reading fluency, vocabulary development and comprehension.

With regard to the top-down processes, Solak and Atlay (2014) are of the argument that in the reading process readers understand the whole sense of a script by using hints in it in association with the background knowledge of the reader. The processes denote that in the course of reading, readers use their personal experiences and views in the interpretation of texts. 'The top-down processing of a text begins in the mind of the reader where the meaning is retrieved from the reader's understanding of the world, outlooks and suppositions. It is presumed that readers trigger their knowledge and contextual knowledge in order to comprehend the script' (Suprajit, (2019). The arguments by Atlay, Solak, and Suprajit (2019) suggest that comprehension as the goal of reading can be attained not only with phonemic awareness, phonics, vocabulary and fluency but also with readers' cognitive skills which include background knowledge. This means reading comprehension may not be accomplished only by identifying the symbols but also it is important to grasp the semantics of the graphic and phonological symbols in the process of reading. The interactive theory implies that the strategies of teaching reading should not only focus on letter-sound association or grapheme-phoneme correspondence but they should also focus on enabling readers to use their background knowledge in the process of reading for comprehension. For example, the teacher can begin with letters of the alphabet and their associated sounds then identify the whole word associated with pictorials as figure 3 illustrates:

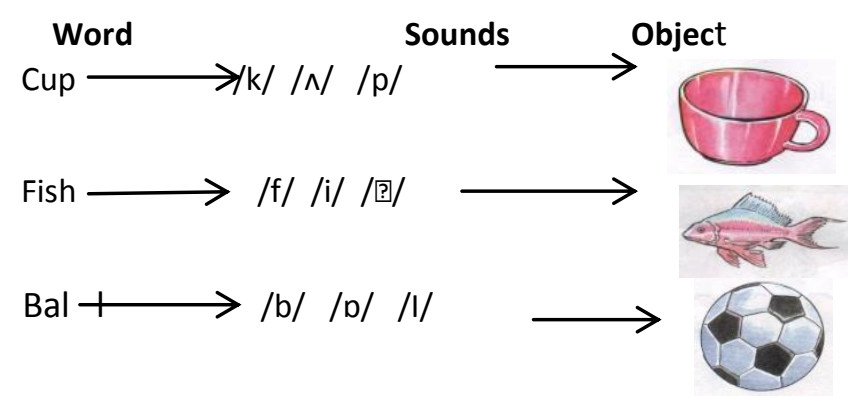

Figure 3: Grapheme phoneme correspondence The use of real objects and pictorials enables children to comprehend how the words they read. 
Pupils easily understand the meaning of the word as they mentally connect it with the things they already know such as a cup with which they take tea or porridge at home, a fish that they eat at home or a ball that they play with their friends.

\section{Methodology}

This study used a qualitative approach which enabled the researchers to accumulate detailed information from respondents on specific information related to the challenges pupils faced in developing phonological awareness skills.

\section{Research Design}

A descriptive research design was employed. The design enabled the researcher to describe in detail the information obtained from respondents through interviews, focus group discussions, test administration and classroom observation on issues related to challenges that pupils faced in learning phonological skills in reading English language in primary schools at Bunda Town.

\section{Population and Sampling}

The target population of this study was 5023 individuals including 4988 pupils, 3 Education Officers, 2 English language tutors, 5 head teachers and 25 teachers. The study constituted one hundred and thirty five respondents who were selected by using both probabilistic and non-probabilistic sampling techniques. The District Education Officer, Ward Education Officers, tutors, head teachers and English language teachers were purposively selected as they were the only ones in their groups. The pupils were selected by using the lottery method.

\section{Research Instruments}

The data were collected through classroom observations, interviews, focus group discussions and tests. The researchers used structured interviews to collect information from education officers, tutors and head teachers. They also used focus group discussions to collect information from teachers. On the other hand, reading and dictation tests were used to assess pupils' awareness on grapheme-phoneme correspondences.

\section{Findings and Discussion}

Findings revealed that pupils faced various challenges in the course of learning phonological skills as follows:

\section{Substituting Sounds in Speech}

Data from the focus group discussions with teachers revealed that some pupils had difficulty in recognizing phoneme differences, hence they tended to substitute sounds in speech. Some of the pupils are influenced by their vernaculars when they read English language words. Major cases of phoneme substitutions took place between the lateral approximant /I/ and the alveolar trill / $\mathrm{r} /$ in speech.

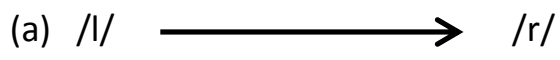

In the pronunciation of words containing such sounds, some pupils in both public and private primary schools had a tendency of substituting these sounds in speech.

Some of the words in which pupils substituted the sounds included: 'load', 'lead', 'leg' and 'look.' Some of the pupils tended to sound out as /raud/, /ri:d/, /reg/ and /ruk/respectively. Also, some pupils substituted the symbols in the words 'graph' /gra:f/ which appeared as 'gilafu' in the dictation test.

The failure of some of the pupils to acquire phonological awareness skills stemmed from various forms of impairment. Some of the pupils failed to demonstrate accurate phonological skills mainly due to some problems related to their speech organs. This situation caused some pupils to substitute sounds such as $/ s /$, the voiceless alveolar fricative with the voiceless interdental fricative / $\theta /$.

(b) $/ S / \quad / \theta /$

(1) Soon /su:n/ becomes / $\theta u: n$ /

Soap /so:p/ becomes / $\theta$ s:p/

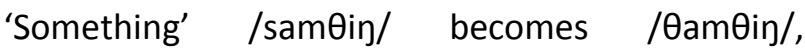
'Sometime'/samtaim/ becomes /Oamtaim/

Also, findings revealed that there were some of the pupils who substituted the voiced alveolar fricative

$/ z /$ with the voiced interdental fricative $/ \delta /$.

(c) $/ \mathrm{z} /$ / ஏ/

$\begin{array}{lrr}\text { (3) } & \text { Zip } & \text { /ðip/ } \\ \text { Zoo } & \text { /ðu: / } \\ \text { Zoom } & \text { / đu:m / }\end{array}$

Moreover, some of the pupils still had trouble with decoding the voiced interdental fricative /ð/ as they replaced it with the voiced alveolar fricative $/ z /$.

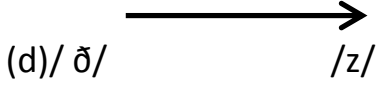


Some of the words that frequently appeared in the speech of pupils include the following:

(4) 'That' /ðat/ was pronounced as /zat/

'This' / đis/ was pronounced as /zis/

'Them' /ðem/ was pronounced as/zem/

A similar case of substituting phonemic sounds was the replacement of the voiced palatal alveolar affricate $/ d_{3} /$ with its voiceless counterpart / $t /$ in several words.

(e) $/ d_{3} /$

(5) 'Judge' /dz^dz/ became/ th^t//

'Jug' /dz^g/ became/t tng/

'Job' /dzbb/ became/tjob/

Therefore, some of the primary school pupils were not able to decode words properly in reading. In addressing this issue, Msabaha's (2018) advised that in order to develop pupils' pronunciation skills it is important to emphasize on reading audibly, sound training and simulation and make them to be part of the entire educational system where learners may learn the basic sounds of English. Furthermore, phonetic alphabet chart should be widely used in association with familiarizing learners with phonetic scripts.

\section{Inserting Vowels in Closed Syllables}

The other challenge that pupils faced was that of inserting vowels in words with closed syllables and consonant clusters.

The dictation tests revealed that some of the pupils had poor phonological skills as they failed to decode words with closed syllable structures. For example, in the dictation test, some pupils orthographically presented the word 'graph'/gra:f/ as 'girafu', and 'gilaff'. Also, some respondents wrote the word 'aspirin' as 'asipilin', 'asipilini' and 'asitilini.' The word 'skeleton was written 'sekeletoni' whereas the word 'fit was written as fiti. The pupils spelled the word 'once' as 'wansi', 'mall' as 'mole' and 'machine' as 'mashine.' The pupils further inserted the vowel /i/ between the consonant clusters and they added the letters ' $i$ ' in the words 'final' and in the word 'fit' which do not end with a vowel sound in its CVC syllable structure.

These findings show that pupils were not able to properly segment English language words into syllables if they inserted vowels within consonant clusters and consonant digraphs.

For example, the insertion of vowels within a word like 'graph' will make the word to mistakenly have three syllables, \$gi\$ \$ra \$ \$u instead of \$gra:f\$. Also, the insertion of vowels causes the word to have an even larger number of phonemes as the segmentation yields to the appearance of six phonemes $/ \mathrm{g} /, / \mathrm{i} /, / \mathrm{r} /, / \mathrm{a} /, / \mathrm{f} /, / \mathrm{u} /$, instead of having only four phonemes /gra:f/.

As it has been seen, the insertion of vowels within consonant blends and in word final positions resulted from pupils being influenced by their home languages including Kiswahili which mainly has open syllable structures. Kiswahili and many other Bantu languages have syllable structures which usually end in vowel sounds. For that matter, when Kiswahili speakers come across words with consonant clusters, they simply insert vowels within the letter blends so as to sound the way they sound out the words in their languages.

This is in agreement with Choge's (2009) propositions that Kiswahili is an open syllable language with two types of syllable skeletal tiers of CV or V. Vowels are syllabic and any syllable therefore must have a vowel or it is formed by a single vowel. Bantu phonological rule requires that all words end in vowels. Kiswahili as a Bantu language also uses its vowels as end phonemes in most of its words.

Thus, pupils will acquire phonological awareness skills in English language, if teachers seriously drill them on pronouncing words with clusters and digraphs. Teachers should also teach pupils the skills that enable them to realize that most of the English words do not end in vowel sounds. Through explicit instructions, pupils will decode English language words and therefore read with relative fluency and comprehension.

\section{Difficulty in Recognizing Silent Sounds}

The other major challenge that pupils faced was recognition of silent sounds in English language. Classroom observations in public primary school ' $A$ ' revealed that some of the pupils had little knowledge of the fact that some English words have letters of the alphabet which are not overtly articulated in speech. For example, some of the pupils pronounced the words 'comb' and 'bomb' with the final sound /b/ clearly heard. These pupils seem to be unknowledgeable of the idea that the voiced bilabial plosive / $b$ / is not part of the sounds clearly articulated in the sounding out of such words. These findings suggest that pupils' failure to recognize silent sounds in English language may affect their phonological awareness skills. For 
example, the insertion of sounds within consonant clusters and digraphs may lead to the following problems:

Wrong segmentation of phonemes in words: The pupils who lacked knowledge on silent sounds will not be able to properly segment phonemes in words. For example, the pupils will segment the word \#bomb\# as /b/, /p/, /m/, /b/ instead of $/ \mathrm{b} / \mathrm{p} / \mathrm{m} /$. The inclusion of silent sounds in word phonemic segmentation obviously leads to misrepresentation of the number of phonemes in the words, hence ill segmentation.

Failure to identify rhyming words: Pupils with little knowledge of silent sounds cannot be able to recognize and identify rhyming words from groups of words. For example, the pupils may fail to understand that the words 'comb' and 'bomb' do not rhyme with the words 'job', 'mob', and 'rob.' The former group consists of words with a bilabial nasal $/ \mathrm{m} /$ in final positions while the latter group consist of words with a voiced bilabial stop /b/ in their final positions. Therefore, these arguments suggest that teachers have to play a big role in imparting the knowledge on silent sounds to pupils so as to enable them pronounce English language words properly and be able to identify rhyming words and segment phonemes in words accurately. Thus, teachers have to employ various techniques of teaching decoding skills that will enable them recognize silent sounds in English words. This will enable pupils gain the skills that such words as 'hour', 'honor', 'honest have, a silent /h/ initially when pronounced.
Failure to Decode Words with Irregular LetterSound Relationships

The findings in the reading test revealed that pupils faced more difficulties decoding words with irregular grapheme-phoneme correspondences. For instance, the words 'died' /daid/, 'steal'/ sti:l/ and 'elephant' /elifənt/ were pronounced as /dedi/, /sitili/, and /elefati/. Similarly, pupils failed to pronounce the word 'laugh' / la:f/ correctly, pronouncing it as /lauged//louged/, /la:fd, /ra:fd/ and /leaf/.

The word 'huge' was pronounced as /hage/, /haj/ and 'pumpkin' as 'pumpkini/ or /pampukini/. The word 'once' was pronounced /onike/ and /onse/ while the word 'upon' was phonologically realized as /upone/, /upon/, /upo/ or /uponi/.

The findings from observation of classroom interactions suggest that some pupils in primary schools still had little knowledge on recognizing the difference between the letters in print and the sounds they represent in speech. They failed to recognize that some words can have more letters but with fewer sounds which stand for the letters in phonological realizations of such words.

In figure 4 , for example, the voiceless labiodental fricative /f/ can be graphically represented by various forms such as ' $f$ ' in word initial for \#food\#, \#fat\# and \#fit\#. Moreover, this sound /f/ can be orthographically represented by the digraphs 'ff', ' $\mathrm{ph}$ ' and ' $\mathrm{gh}$ ' in the words \#coffee\#/kpfi/, \#phone\# /fəun/ and \#laugh\# /la:f/ respectively.

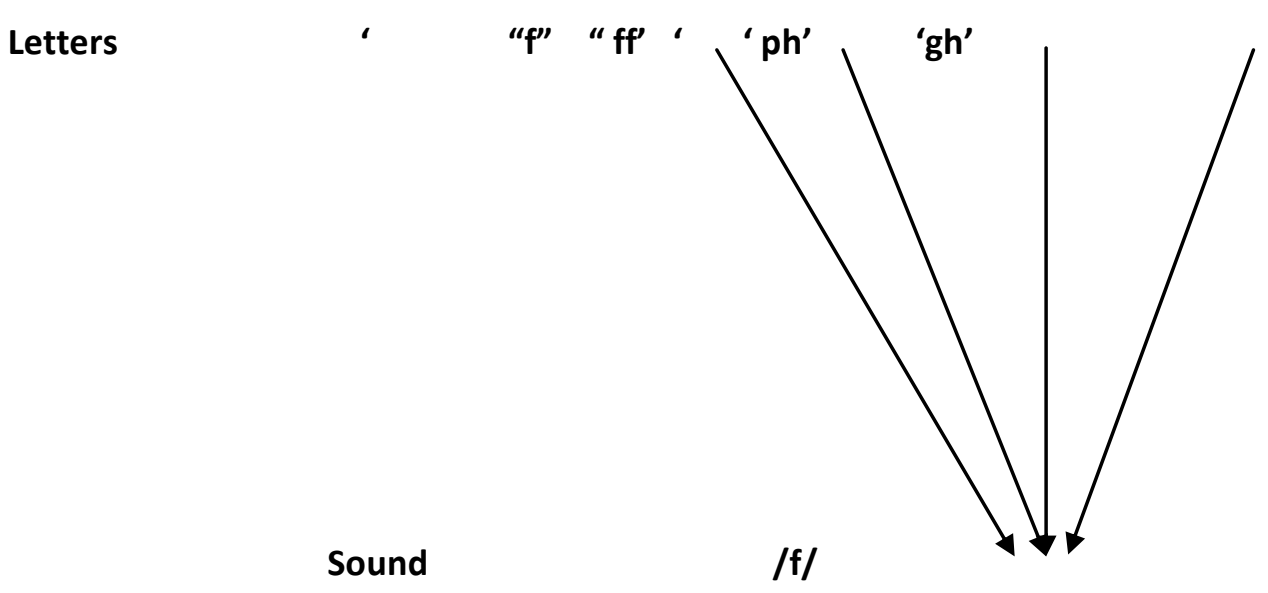

Figure 4: Grapheme-Phoneme Correspondences for the Phoneme /f/

This therefore suggests that teachers have a big role of teaching the phonological skills of identifying sounds in words so as to enable them to be competent in the area of grapheme-phoneme 
correspondences. Teachers have to apply appropriate methods that will enable the pupils recognize the letters of the alphabet and their corresponding sounds. These arguments concur with Rao (2018) who contended that in order to enable learners to read English words with irregularities, special notations i.e. IPA symbols are needed. This will make them understand the intelligibility of the pronunciation and the spellingdesigned of the English words. Learners need to be familiar with all the possible spelling rules and be aware of the numerous possible letter-sound combinations in order to master English spelling and pronunciation.

Therefore, teachers have to find out the best methods and techniques of familiarizing pupils with the irregular orthography-phonology mappings in English language so as to enable pupils to easily decode English language words, read fluently and comprehend texts. These arguments are also in partial congruence with The National Reading Panel's (2000) assertions that phonological awareness is influential in developing learners' reading fluency and comprehension.

\section{Difficulty in Recognizing Homophones}

Findings revealed that some pupils had difficulties in representing phonemes into graphic symbols as a result of homophony (words with the same pronunciation but with different spellings). For example, in the focus group discussion with teachers, it was revealed that one of the challenges facing pupils in dictation lessons is the presence of lexical items that have a similar or almost the same phonological realization but with a contrast in orthography and semantics. Teachers maintained that in dictation lessons, pupils usually write quite different words simply because the words read in the dictation are homophonous to the ones that pupils find themselves writing. Examples of words that some of the teachers identified include such pairs of homophones as 'see'/ 'sea'/, 'son'/ 'sun', 'meat' / 'meet,' 'hear' / 'here,' 'write'/ 'right', 'hit'/ 'heat,' 'bit'/ 'beat,' 'full'/ 'fool', 'pull'/ 'pool' and 'week'/ 'weak'. Moreover, further findings revealed that some of the pupils made spelling errors due to homophony. For example, in dictation test 1 , some of the pupils graphically represented the words 'goat' in place of 'got', 'feet' for 'fit', 'beat' for 'bit', 'heat' for 'hit' and 'leap' for 'lip'.

Therefore, based on these findings, it is obvious that pupils would not identify words easily mostly in dictation lessons if teachers did not employ various techniques of teaching them. The pupils represented other words due to the confusion brought about by the similarities in the way the words sound. These findings echoed what Sipra (2013) proclaims that homonyms as words with same pronunciations but different in spellings along with different meanings is another area of orthography that causes obstacle in learning English. In order to reduce such problems related to homophony, it is appropriate to use appropriate contexts which will play a vital role in eliminating confusions in reading and dictation lessons.

\section{Difficulty in Identifying Phonemes by Segmenting Words}

Findings revealed that some of the primary school pupils had trouble with identifying phonemes in word segmentation processes. For example, in the course of identifying phonemes in words in public primary school ' $A$ ', some of the pupils segmented the words 'ball' 'tall', 'took' 'look', 'coat' and 'bomb' into four sounds each. Pupils counted letters of the alphabet instead of sounds (phonemes) in the words. These findings reveal that the pupils failed to segment the words into phonemes due to failure to differentiate between letters of the alphabet in print and the phonemes in the articulation of the words when reading.

Findings from the classroom observation suggest that some of the pupils in primary schools fail to segment sounds in words as a result of little knowledge on digraphs. In the process the pupils failed to recognize that there are some combination of letters that are phonologically represented by individual phonemes as in the case of 'book' /buk/ in which the vowel digraph 'oo' stands for the back rounded vowel /u/.

These findings imply that if teachers do not employ several techniques to familiarize pupils with digraphs, the pupils will not be able to properly segment words into phonemes. It is the role of the teachers to familiarize the pupils with letter blends that stand for individual speech sounds when articulated. This will enable the learners to understand that digraphs are pairs of letters that represent individual phonemes.

For example, the digraph'll' in 'ball' and 'tall' stand for a lateral approximant / $/$. That makes the two words to be segmented into three sounds each 'tall' /t/, /o:/, /l/ and 'ball' /b/ / /:/,/l/. Similarly, the digraphs 'oo' in 'took' and 'look' stand for the back 
rounded vowel /u/. Also, the digraph 'oa' in coat stands for the back mid-low rounded long vowel / $\mathrm{J}: /$, hence /kJ:t/. Therefore, the knowledge on digraphs will enable the pupils to differentiate letters of the alphabet and the speech sounds (phonemes) that represent those letters in speech. If teachers apply appropriate methods and techniques of enhancing phonological skills, pupils will be able to segment words into phonemes, hence read fluently. These arguments are in congruence with the assertion by Ligembe (2014) who proclaims that the understanding of digraphs as two letters of the alphabet which represent individual phonemes will enable pupils to read words properly without breaking the digraphs or omitting parts of them as in Kiswahili words 'dhahabu' (gold) and 'dhehebu' (religious denomination) in which the digraph ' $d h^{\prime}$ ' sound as a voiced interdental fricative $/ ð /$. He argues that pupils with low phonological awareness will read such words as 'dahabu' and 'dehebu' which is a wrong phonological representation of such orthographic symbols of Kiswahili.

\section{Failure to Decode Consonant Clusters in Words}

The other big challenge that pupils faced is associated with decoding words with consonant clusters. The data obtained in the dictation tests revealed that some pupils face difficulties in properly representing words with consonant clusters into orthographic symbols. For example, in the dictation tests, some respondents inserted the vowel letter ' $i$ ' and ' $e$ ' within the consonant blends 'sp' and ' $g r$ ' and 'sk' in the words 'aspirin', 'graph' and 'skeleton.' They graphically represented the words as 'asipilini', 'asitilini', 'girafu"gilafu' 'seretoni' and 'sekeletoni.'

In the second dictation test, the respondents were required to transform the words read by the teacher into graphic symbols. The test dominantly contained words with irregular orthography-phonology mapping. The words included 'laugh' /la:f/, 'rough' /rıf/, 'honour' /onə(r)/, 'mall' /mo:l/ 'once'/w^ns/,'theme' / $\theta 1: \mathrm{m} /$,'them' / đem,/'graph' /gra:f/,'soup' /su:p/ and 'soap'/so:p/.

Findings obtained from the dictation test 2 reveal that there are some pupils with low skills in representing phonemes into graphic symbols. For example, some of the respondents used the letter ' $f$ ' instead of the digraph ' $\mathrm{ph}$ ' in the word final for 'laugh' and 'graph,' hence they graphically represented them as 'laf', 'raf', and 'rouf.' Also, some respondents spelled the words 'honour' as 'hanna' while the word 'hour' was spelled as 'hawa.' The word 'soup' was spelled as 'sup'.'suap' 'supp' while the word 'source' was graphically represented as 'seos', 'sos' and 'soth.' The pupils simply spelled the words in the manner such words sounded in the speech of the reader. Again, the word 'once' troubled some of the respondents as they spelled it as 'wans', 'ones', 'wanse" 'wains' and 'wonse.'

General findings obtained from the reading test further revealed that some pupils still had difficulties in associating letters with sounds (grapheme - phoneme correspondence). For example, the sounding of the word 'once' as /onike/ suggests that pupils were not aware of the various sounds that represent the letter ' $o$ ' in speech. The letter can sound as $/ \mathrm{p} /$ in the word 'on'/ $\mathrm{pn} /$, and it can sound as / $\mathrm{w} /$ / in the words like 'one'/ wAn/ and 'once'/wıns/. With regard to the words 'upon', 'pumpkin' and 'huge' the pupils failed to pronounce them properly mainly due to little understanding of the various ways letter ' $u$ ' is realized phonologically. The pupils pronounced the three words as /upone/, /pumpikini/ and /haj/ respectively. The proper pronunciations of these words indicate that letter ' $u$ ' sounds as $/ \partial /$ and $/ \Lambda /$ in the word 'upon' and 'pumpkin'respectively, whereas in the word 'huge' the letter ' $u$ ' sounds as a combined velar glide and the back high rounded vowel hence /hjudz/.

The pupils also failed to realize that the combination of the letters (digraph) 'gh' stands for the voiceless labiodental fricative /f/ in such words as 'laugh'/ la:f/ and 'rough'/ ra:f/. Also the low performing respondents failed to sound out the digraph ' $a u^{\prime}$ ' as a long vowel /a:/ in the word 'laughed.' The findings further show that the poor performers sounded out the word 'once' as /onike/, and /onse/ while the word 'upon' was phonologically represented as /upone/, /uponi/, /upon/ and/upo/.

Furthermore, it has been learned that some of the pupils failed to pronounce some of the words with correct phonemic representation due to the influence of mother tongues and Kiswahili as the language of their daily communication. For example, the pupils who substituted the phonemes /I/ with $/ \mathrm{r} /$ and $/ \mathrm{b} /$ with $/ \mathrm{p} /$ in the words 'look' and 'book' which they pronounced as /pu:k/ and /ru:k/ exhibited the influence of their vernacular language on English language. This is due to the fact that languages have a tendency of influencing each other. In most cases, the language acquired earlier 
tends to influence the one that comes later. This concurs with what Mtallo and Mwambula (2018) substantiate that one language may have an influence in learning the other language whereby the influence may be intensely realized in various areas such as phonology, morpho-syntax as well as terminology.

With regard to those pupils who inserted the front unrounded high vowel / $\mathrm{u} /$ in word final position of 'book', it suffices to assume that there is a great influence of Kiswahili syllable structures in pupils' pronunciation of English language words. This is still a case similar to that identified by Msabaha (2018) that most of Kiswahili words end in vowel sounds and that affect pronunciation of English language words as well. That is to say, majority of Kiswahili words have open syllables. This makes the speakers of Kiswahili pronounce words of other languages in the manner they pronounce Kiswahili words.

Thus, it can be argued that teachers are obliged to employ efficient techniques and strategies of teaching that will enable pupils do away with wrong pronunciation in English language that result from the influence of mother tongues. Adequate drilling on sounds has to be done to the pupils so as to enable them be conversant with the correspondences between the graphic symbols and phonological symbols in English language reading.

With regard to the problem of pupils in identifying the sounds yielded from digraphs, phonics as a method that drills on letter-sound relationships can also be used to solve that problem. According to Farrel and Hunter (2010), a digraph includes two letters that spell one sound. Digraphs that spell consonant sounds include the letter pairs sh, ch, th and ph, while the digraphs that spell vowel sounds include the letter pairs ee, ea, oo, ou, oe, oo and au. They further assert that it is imperative to apprehend that vowel digraphs are different from diphthongs as the former are letters while the latter are sounds involving two movements of the mouth in their articulation.

Thus, the above arguments suggest that unless pupils are explicitly instructed on decoding unfamiliar words, including those with digraphs, they will not be able to sound out the letters in such words and therefore fail to read effectively. Therefore, it is the role of the teacher to identify all the digraphs for both vowels and consonants and drill pupils on how to transform such digraphs into their phonological realizations.
These views seem to be in partial agreement with The National Reading Panel's (2000) propositions that as soon as children know enough letters or spelling patterns to allow the decoding of new words, further teaching should then include opportunities to apply phonics knowledge to decode even more complex words. The panel asserts that phonics instruction accomplishes more than only teaching the pupils to associate simple letters with their associated sounds.

Similarly, it is argued that the ability to use one's familiarity with grapheme-phoneme associations, including awareness of letter patterns, for the sake of appropriately articulating lexical items in print is technically known as decoding (Güldenoğlu, 2016).

The analysis also indicates that the most problematic area in pupils' phonological awareness is related to decoding words with irregular grapheme-phoneme correspondence. Teachers, therefore, are supposed to apply appropriate phonics strategies of enhancing phonological skills to pupils so as to enable them write English words with correct spelling and also read English language words with appropriate pronunciation. With a lot of practices and frequently using the dictionary, pupils can develop the skills in not only pronunciation but also in spelling and reading comprehension.

In another development, the study findings revealed that pupils in public schools faced more challenges in acquiring phonological awareness skills because they started learning English language late compared to their counterparts in English medium primary schools. The pupils in public schools are exposed to English language learning in standard three, whereas their counterparts in English medium pre and primary schools begin to learn English from standard one. This implies that pupils in English Medium Pre and Primary schools get exposure to phonics-based activities as early as possible and therefore, they become more conversant with phonological activities than their counterparts in public primary schools who start learning English language in standard three. This suggests that pupils in public primary schools start to learn English language at the time when their counterparts in English medium schools enter the third year of acquainting the language. Hence, it suffices to assume that the early commencement of English language learning in English medium schools is the pillar of the pupils' success in acquiring phonological awareness skills. 
This is in line with what Lenneberg (1967) advocates in the Critical Period Hypothesis ( $\mathrm{CPH}$ ) that language is best learned during the early years of childhood and that after about the first dozen years of life, everyone faces certain limitations in the ability to pick up a new language. Language learning after the close of the critical period would result in incomplete acquisition.

Commenting on the roots of $\mathrm{Li}$ (2014) submits that ideas regarding the optimal age for language acquisition were first introduced by Penfield and Roberts (1959) as cited in Li (2014) who argued that language acquisition is most efficient before age nine when the human brain becomes stiff and rigid. Therefore, it can be contended that if all the pupils in primary schools start learning English language from the kindergarten level, they will be exposed to alphabetic skills as early as possible. This may enable them to gain phonological awareness skills which will in turn enable them to read fluently and easily comprehend texts.

Findings on the challenges related to irregular words identified to be a hindrance in dictation lessons imply that teachers have to apply various techniques of teaching the pupils on the recognition of homophonous words and others with irregular letter-sound correspondence.

It was revealed that pupils' failure to decode words in dictation lessons sometimes results from the structure of English language especially on the question of homophones (words with similar phonological realizations but with variations in orthography and semantics).

The findings imply that pupils may not be able to transform phonological symbols into graphic symbols for homophones unless teachers employ some techniques that will facilitate easy recognition of words by the pupils. For instance, teachers can use contexts that will enable pupils to recognize the intended words in the dictation tests. These arguments seem to confirm what Sipra (2013) who substantiates that for the learners to gain understanding on homophones, it is important that special contexts are used. The context may enable the listeners to understand the exact lexical item that is referred to by the reader in a dictation test. Therefore, general findings on pupils' phonological awareness skills suggest that the pupils who perform poorly in demonstrating phonological skills require deliberate and explicit instructions on how to realize different phonemes that represent the alphabetic letters in speech. Unless pupils receive adequate phonics instructions, they may not be able to have their phonological awareness skills improved.

\section{Conclusions and Recommendations}

The study concludes that pupils' phonological awareness skills in English language are low as the majority of pupils cannot properly decode English phonemes in reading. There is a great deal of influence from mother tongues and other vernaculars on pupils' acquisition of phonological awareness. When two or more languages come into contact, they influence each other as it is the case of English and Kiswahili. Pupils faced a lot of challenges in identifying silent sounds in English, hence, incapable of pronouncing English words appropriately. This suggests that pupils' ability to segment words will be low as they include silent sounds in speech. As a matter of fact, if teachers do not employ a lot of efforts in sound drilling, pupils will not be in a better position to develop phonological awareness skills.

Efforts are needed to help the pupils acquire phonological skills and be able to read with efficiency. It is important that teachers employ phonics strategies and techniques to enhance pupils' skills in letter-sound relationships. This will also be accomplished through familiarizing the pupils with the IPA symbols and through frequent use of the English pronouncing dictionary. Moreover, teachers in English medium primary schools and those in the public schools should work closely together in addressing the methods of imparting phonological skills to pupils; mainly through phonics strategies such as blending and segmentation, substitution, deletion and rhyming games.

\section{References}

Angonsto, A., Sánchez, P., Álvarez, M., Cuevas, I., \& León, J. A. (2013).Evidence for top-down processing in reading comprehension of children. Psicología Educativa, 19(2), 83-88.

Choge, S. (2009). Understanding Kiswahili vowels. Journal of Pan African Studies, 2 (8),62-77.

Farrel, L. T.,\& Hunter, M. (2010). The Difference between Digraphs and Diphthongs. Founding Partners, Readstars.

Gilakjani, A. P., \&Sabouri, N. B. (2016).A study of factors affecting efl learners' reading comprehension skill and the strategies for 
improvement. International Journal of English Linguistics, 6(5) 180-187.

Gonzalez, A. M. G. (2017). Reading Comprehension in English as a Foreign Language Setting: Teaching Strategies for Sixth Graders Based on the Interactive Model of Reading. Bogota Colombia.

Güldenoğlu, B. (2016). The effects of syllableawareness skills on the word-reading performances of students reading in a transparent orthography. International Electronic Journal of Elementary Education, 8(3), 425-442.

Kasim, U., \&Raisha, S. (2017). EFL students' reading comprehension problems: linguistic and non-linguistic complexities. English Education Journal, 8(3), 308-321.

Lenneberg, E. H. (1967). Biological Foundations of Language. New York: Wiley

LI, Q. (2014) Research on age-related factors in foreign language learning. International Journal of Language and Linguistics.

Ligembe, N. N. (2014). Factors Affectingt the Acquisition of Reading Skills in Kiswahili in Primary Schools: The Case of Musoma Municipal and Misungwi District Councils. (Doctoral dissertation, The Open University of Tanzania).

McArthur, G., \& Castles, A. (2017). Helping children with reading difficulties: Some things we have learned so far.Npj Science Of Learning, 2(1), 1-4.

McRae, S.D (2012) Utilization the Interactive Reading Model in continuing Education Course. School of International Training. MATESOL.

Mendez,L. E. C., and Lliviganay, T.M.L. (2017). The Use of Bottom-Up and Top- Down Processing as an EFL Teaching Tool Based on Schema Theory to Develop Reading Skills in $9^{\text {th }}$ Graders at TecnicoSelensini High School.

Msabaha, J. A. (2018). The Effect of Kiswahili on Teaching of English Pronunciation at
Primary Schools: The Case of Songea Municipality (A Dissertation, the Open University of Tanzania).

Mtallo, G. R., \&Mwambula, H. A. (2018). The Phonological Influence of Ethnic Community Languages in Learning Kiswahili, a Case of Kinyakyusa in Mbeya, Tanzania.

National Reading Panel (US), National Institute Of Child Health, \& Human Development (US). (2000). Teaching Children To Read: An Evidence-Based Assessment of The Scientific Research Literature On Reading And Its Implications for Reading Instruction: Reports of the Subgroups

Ngabut, M. N. (2015). Reading theories and reading comprehension. Journal on English as a Foreign Language, 5(1), 25-36.

Rao, V.C. (2018). English spelling and pronunciation: A brief study. Journal for Research Scholars and Professionals of English Language Teaching, 2, 1-10.

Sipra, M.A (2013) Impact of English orthography on L2 acquisition English language teaching.

Canadian Centre of Science and Education.6(3), 116-124.

Solak, E., \& Altay, F. (2014). The Reading strategies used by prospective English teachers in Turkish ELT context. Online Submission, 1(3), 78-89.

Suraprajit, P. (2019). Bottom-up vstop-down model: the perception of reading strategies among Thai University students. Journal of Language Teaching and Research, 10(3) 454-460.

Uwezo (2019): Are Our Children Learning? Uwezo Tanzania Learning Assessment Report. Dar es Salaam: Twaweza East Africa.

Woldmo, R. (2018). Phonological awareness: An Instructional and Practical Guide for the Kindergarten Classroom. Retrieved December 21, 2020 from https://www.uwo.ca/fhs/lwm/teaching/dld2018-19/woldmo-PAGuidekindergarten http://linguistics.ucla.edu/people/keating/I PA/IPA_charts_201. 